\title{
In vitro cytotoxicity of (-)-EGCG octaacetate on MDAMB-231 and SKHep-1 human carcinoma cells: A pharmacological consideration on prodrug design
}

\author{
STANTON HON LUNG KOK ${ }^{1}$, RAYMOND SIU MING WONG ${ }^{2}$, ROBERTO GAMBARI ${ }^{3}$, FILLY CHEUNG ${ }^{1}$, \\ WING SZE LAM ${ }^{1}$, FUNG YI LAU ${ }^{2}$, GREGORY YIN MING CHENG ${ }^{2}$, CHOR HING CHENG $^{1}$, KIM HUNG LAM ${ }^{1}$, \\ SAU HING CHAN ${ }^{1}$, JOHNNY CHEUK ON TANG ${ }^{1}$, CHUNG HIN CHUI ${ }^{1,2}$ and KWOK PING HO ${ }^{1}$

\begin{abstract}
${ }^{1}$ Department of Applied Biology and Chemical Technology, Hong Kong Polytechnic University; ${ }^{2}$ Department of Medicine and Therapeutics, Prince of Wales Hospital, The Chinese University of Hong Kong, Hong Kong, P.R. China;

${ }^{3}$ BioPharmaNet, Department of Biochemistry and Molecular Biology, The University of Ferrara, Ferrara, Italy
\end{abstract}

Received June 18, 2008; Accepted September 4, 2008

DOI: 10.3892/ijmm_00000093

\begin{abstract}
Esterification of acetate with generic pharmaceutical compound has been commonly employed to produce ester prodrug for improving its potency when compared with the mother compound. Acetate, on the other hand, has been recognized to have inhibitory effect on the respiratory biochemistry. Here we demonstrate that acetate at a concentration of $400 \mu \mathrm{M}$ exhibited significant growth inhibitory activity on two human cancer cell lines, the MDAMB-231 breast cancer and the SKHep-1 hepatoma cell lines. To establish the ester prodrug with multi-acetate ester conjugates as our experimental model, one molecule of (-)-epigallocatechin gallate was required to conjugate with eight molecules of acetate forming the corresponding (-)-epigallocatechin gallate octaacetate prodrug. Chemical structure of this epigallocatechin gallate octaacetate ester prodrug was confirmed by both ${ }^{13} \mathrm{C}$ and ${ }^{1} \mathrm{H}$ nuclear magnetic resonance spectra and mass spectrometry. Further cytotoxic assay using both MDAMB-231 and SKHep-1 human carcinoma cell lines showed that acetate at a concentration of $400 \mu \mathrm{M}$ exhibits an additional cytotoxic effect with (-)-epigallocatechin gallate at a concentration of $50 \mu \mathrm{M}$, although the additional effect was not as high as (-)-epigallocatechin gallate octaacetate ester prodrug alone at a concentration of $50 \mu \mathrm{M}$. Our results thus raise a pharmacological consideration of using multi-acetate conjugate as the ester prodrug where the release of free acetate by esterase could be part of the explanation for the improved in vitro cytotoxicity.
\end{abstract}

Correspondence to: Dr C.H. Chui and Dr K.P. Ho, Department of Applied Biology and Chemical Technology, Hong Kong Polytechnic University, Hong Kong, P.R. China

E-mail: chchui@graduate.hku.hk bckpho@inet.polyu.edu.hk

Key words: acetate,(-)-EGCG, (-)-EGCG octaacetate prodrug

\section{Introduction}

The conjugation of acetate to generic drug is one of the common methods to prepare the corresponding prodrug. The presence of esterase could hydrolyse the ester bond and this could result in releasing the active form of the drug, able to exert its pharmaceutical action. Such ester based prodrugs were shown to have improved permeability to cells $(1,2)$.

On the other hand, acetate has been shown to have effects on intermediary metabolism in heart, accordingly to evidence demonstrating that exposure of cardiac tissue to acetate interrupts glycolysis (3). The underlying mechanistic action might involve the feedback inhibitory effect of phosphofructokinase by the condensation product of acetyl Coenzyme A in the citric acid cycle, the citrate (4).

We were interested to verify whether the by-product of acetate linked prodrug, the acetate, would also have profound biological effects on cancer cells in vitro. To address this issue, we investigated the possible concentration of acetate ions that would possess significant growth inhibitory potential on two human cancer cell lines, including the MDAMB-231 breast cancer cells and SKHep-2 hepatoma cells. Then (-)-epigallocatechin gallate (EGCG) was used as a simulatory model to synthesize its octaacetate ester 'prodrug' and the chemical structure of the resulting synthetic product was confirmed by ${ }^{1} \mathrm{H},{ }^{13} \mathrm{C}$ nuclear magnetic resonance (NMR) spectra and mass spectrometry (MS). We compared the growth inhibitory activity of acetate ion, (-)-EGCG and (-)-EGCG octaacetate ester prodrug on the proliferation of these two human carcinoma cell lines. Our results showed that acetate has additional inhibitory action on these two cancer cell lines when administered together with (-)-EGCG. We suggest that a pharmacological consideration on prodrug design should be considered if multiple acetates are used to produce the corresponding ester prodrug.

\section{Materials and methods}

Synthesis of (-)-EGCG octaacetate ester. Unless otherwise indicated, all reactions were carried out under nitrogen 
<smiles>O=C(OC1Cc2c(O)cc(O)cc2OC1c1cc(O)c(O)c(O)c1)c1cc(O)c(O)c(O)c1</smiles><smiles>CC(=O)Oc1cc(OC(C)=O)c2c(c1)OC(c1cc(OC(C)=O)c(OC(C)=O)c(OC(C)=O)c1)C(OC(=O)c1cc(OC(C)=O)c(OC(C)=O)c(OC(C)=O)c1)C2</smiles>

Figure 1. Reaction scheme for the synthesis of (-)-EGCG octaacetate ester.

atmosphere. NMR spectra were recorded on a Varian $500 \mathrm{MHz}$ Fourier transform spectrometer. ${ }^{1} \mathrm{H}$ and ${ }^{13} \mathrm{C}\left[{ }^{1} \mathrm{H}\right] \mathrm{NMR}$ spectra were recorded relative to residual protiated solvent; a positive value of the chemical shift denotes a resonance downfield from TMS. Mass analyses were performed on a Finnigan model Mat 95 ST mass spectrometer. (-)-EGCG was purchased from Sigma-Aldrich. All other chemicals were purchased from commercial suppliers and used without further purification. Pyridine was freshly distilled from sodium under nitrogen. Acetic anhydride was freshly distilled prior to use. All reactions were monitored by analytical thin-layer chromatography (TLC) on Merck aluminum-precoated plates of silica gel $60 \mathrm{~F}_{254}$ with detection by spraying with $5 \%(\mathrm{w} / \mathrm{v})$ dodecamolybdophosphoric acid in ethanol and subsequent heating. E. Merck silica gel 60 (230-400 mesh) was used for flash chromatography. Chemical structure was confirmed by NMR including ${ }^{1} \mathrm{H}$ and ${ }^{13} \mathrm{C}$ spectra and MS, respectively $(5,6)$.

To a solution of the (-)-EGCG (10 $\mathrm{mg}, 0.02 \mathrm{mmol})$ in pyridine $(2 \mathrm{ml})$ was added acetic anhydride $(0.5 \mathrm{ml})$ at room temperature, and the resulting mixture was stirred overnight at room temperature. The reaction mixture was dried under vacuum. The resulting crude solid was dissolved in dichloromethane followed by flash chromatography (hexane-ethyl acetate, 4:1). Fig. 1 shows the reaction scheme.

Cell lines and cell culture. Two human carcinoma cell lines, the MDAMB-231 breast cancer and SKHep-1 hepatoma cell lines, were kindly provided by Professor Gregory Yin Ming Cheng, Department of Medicine and Therapeutics, Prince of Wales Hospital, The Chinese University of Hong Kong. Both carcinoma cell lines were maintained in RPMI-1640 medium (Sigma Chemical) supplemented with 5\% of heat inactivated fetal bovine serum (Hyclone) together with antibiotics involving penicillin and streptomycin. Cells were allowed to grow in a humidified cell culture incubator keeping at $5 \%$ carbon dioxide (Nuaire).

Preparation of compounds for cancer cell culture study. Sodium acetate was purchased from Sigma Chemical and dissolved in sterile distilled water to a final stock concentration of $400 \mathrm{mM}$. Both of the (-)-EGCG and synthetic (-)-EGCG octaacetate ester prodrug were dissolved in dimethylsulfoxide (DMSO) to a final stock concentration of $50 \mathrm{mM}$. All of them were kept at $-20^{\circ} \mathrm{C}$ in aliquots until further use.
Antiproliferative and cytotoxic tests. The employed cells were seeded in a 96-well microtitre plate on the first day. On the second day, growth medium was changed and the different tested compounds were added. The maximum concentration of DMSO used never exceeded $0.01 \%$ by volume. After $48 \mathrm{~h}$, the intracellular ATP level was measured by using the ATPlite-1step kit (Perkin-Elmer, Life Sciences) for antiproliferative and cytotoxic activity test. The resulting luminescence was recorded according to the instruction manual provided (7).

Morphological monitoring of sodium acetate-treated MDAMB-231 and SKHep-1 cells. Any morphological changes from $400 \mu \mathrm{M}$ of sodium acetate-treated MDAMB-231 and SKHep-1 carcinoma cells were recorded by investigation under an inverted microscope after $48 \mathrm{~h}$ of incubation (8).

Statistical analysis. Student's t-test was used in data analysis where results were considered as statistically significant when p-value was $<0.05$ when compared with untreated control.

\section{Results and Discussion}

Synthesis of (-)-EGCG octaacetate ester. We have successfully synthesized the (-)-EGCG octaacetate ester as chemical structure was confirmed by ${ }^{1} \mathrm{H}$ (Fig. 2) and ${ }^{13} \mathrm{C}$ (Fig. 3) NMR spectra and MS. The chemical reaction gave the octaacetate (15.4 mg, 89\%) as a white solid: $R f=0.58$ (hexane-ethyl acetate, 4:1); ${ }^{1} \mathrm{H} \mathrm{NMR}\left(\mathrm{CDCl}_{3}, 500 \mathrm{MHz}\right): \delta 2.23(6 \mathrm{H}, \mathrm{s})$, $2.24(3 \mathrm{H}, \mathrm{s}), 2.26(3 \mathrm{H}, \mathrm{s}), 2.27(9 \mathrm{H}, \mathrm{s}), 2.28(3 \mathrm{H}, \mathrm{s}), 2.99$ $(1 \mathrm{H}, \mathrm{dd}, J=18$ and $2.0 \mathrm{~Hz}), 3.06(1 \mathrm{H}$, dd, $J=18$ and $4.5 \mathrm{~Hz})$, $5.18(1 \mathrm{H}, \mathrm{s}), 5.63-5.64(1 \mathrm{H}, \mathrm{m}), 6.61(1 \mathrm{H}, \mathrm{d}, J=2.0), 6.73$ $(1 \mathrm{H}, \mathrm{d}, J=2.0), 7.23(2 \mathrm{H}, \mathrm{s}), 7.62(2 \mathrm{H}, \mathrm{s}) ;{ }^{13} \mathrm{C} \mathrm{NMR}\left(\mathrm{CDCl}_{3}\right)$, $\delta 20.1,20.1,20.5,20.7,21.0,25.9,68.0,76.5,108.0,109.0$, $109.4,118.8,122.3,127.4,134.4,135.0,138.9,143.3,143.4$, 149.6, 149.7, 154.7, 163.5, 166.2, 166.7, 167.4, 167.5, 168.3, 168.8; LRMS (ESI) $\mathrm{m} / \mathrm{z}$ (relative intensity) $817\left([\mathrm{M}+\mathrm{Na}]^{+}\right.$, 100); HRMS (ESI) calcd for $\mathrm{C}_{38} \mathrm{H}_{34} \mathrm{O}_{19} \mathrm{Na} 817.1586$, found 817.1574 . The presence of pyran ring protons of catechin can be confirmed by 2D COSY correlation experiment as we can find positive signals of three separate protons at $\delta 3.02, \delta 5.18$ and 85.63 (Fig. 4).

Antiproliferative and cytotoxic effects of $400 \mu \mathrm{M}$ acetate. To evaluate the antiproliferative and cyctoxic effects of sodium 


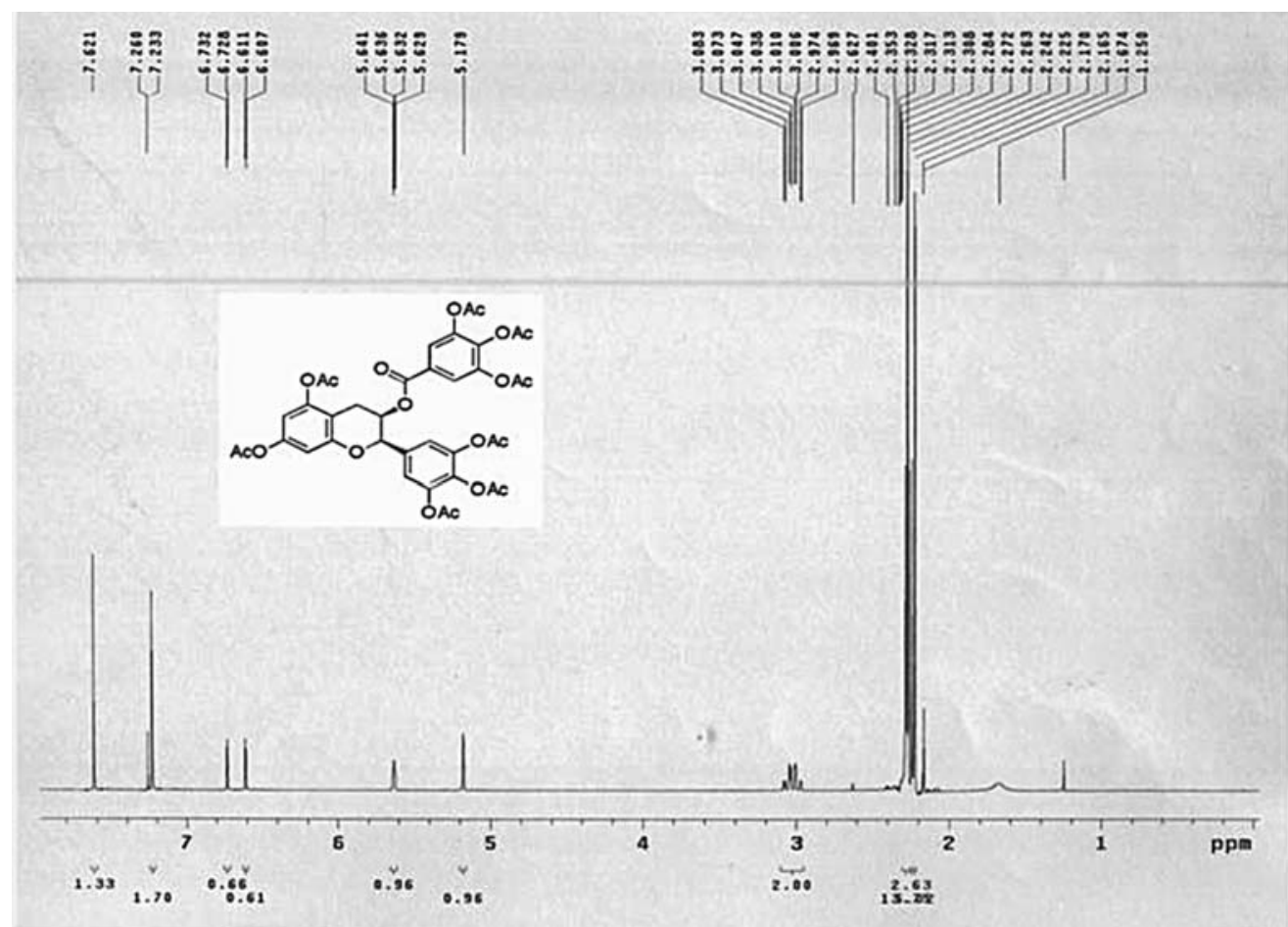

Figure 2. ${ }^{1} \mathrm{H}$ NMR spectrum of (-)-EGCG octaacetate ester.

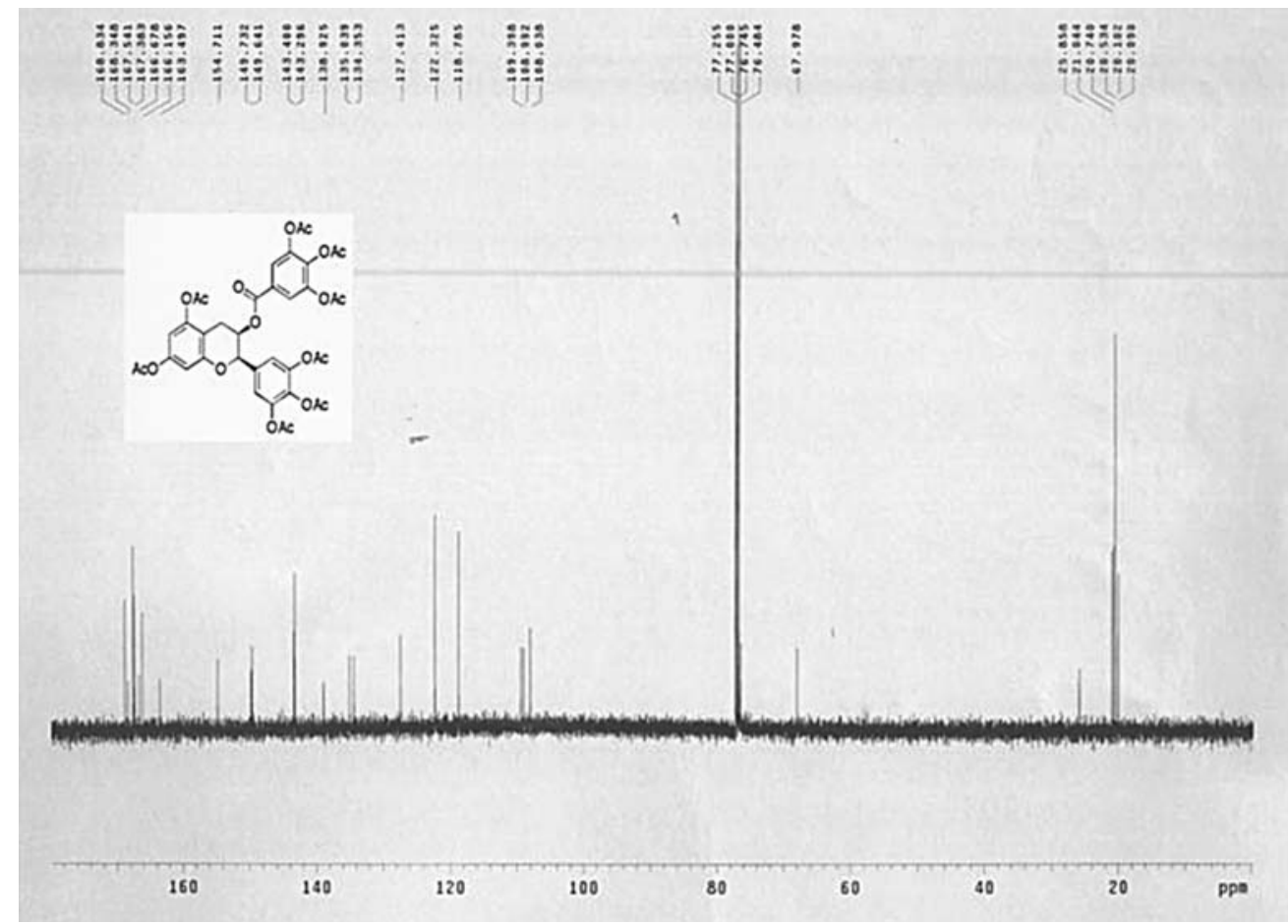

Figure $3 .{ }^{13} \mathrm{C}$ NMR spectrum of (-)-EGCG octaacetate ester.

acetate on both MDAMB-231 and SKHep-1 carcinoma cell lines in vitro, serial concentrations of sodium acetate, ranging from 50 to $400 \mu \mathrm{M}$, were tested. We observed that significant inhibitory effect on both cancer cell lines at $400 \mu \mathrm{M}$ sodium acetate (Fig. 5A). Morphological investigations suggest that SKHep-1 hepatoma cells are more susceptible to sodium acetate induced apoptosis, since apoptotic features, including round cells, bubbling of cell membrane and cell shrinkage (compare panels E to D in Fig. 5) were more obvious than in MDAMB-231 breast cancer cells (compare panels C to B in Fig. 5).

Growth inhibitory effects of (-)-EGCG, (-)-EGCG octaacetate ester and acetate. After obtaining the information on growth 


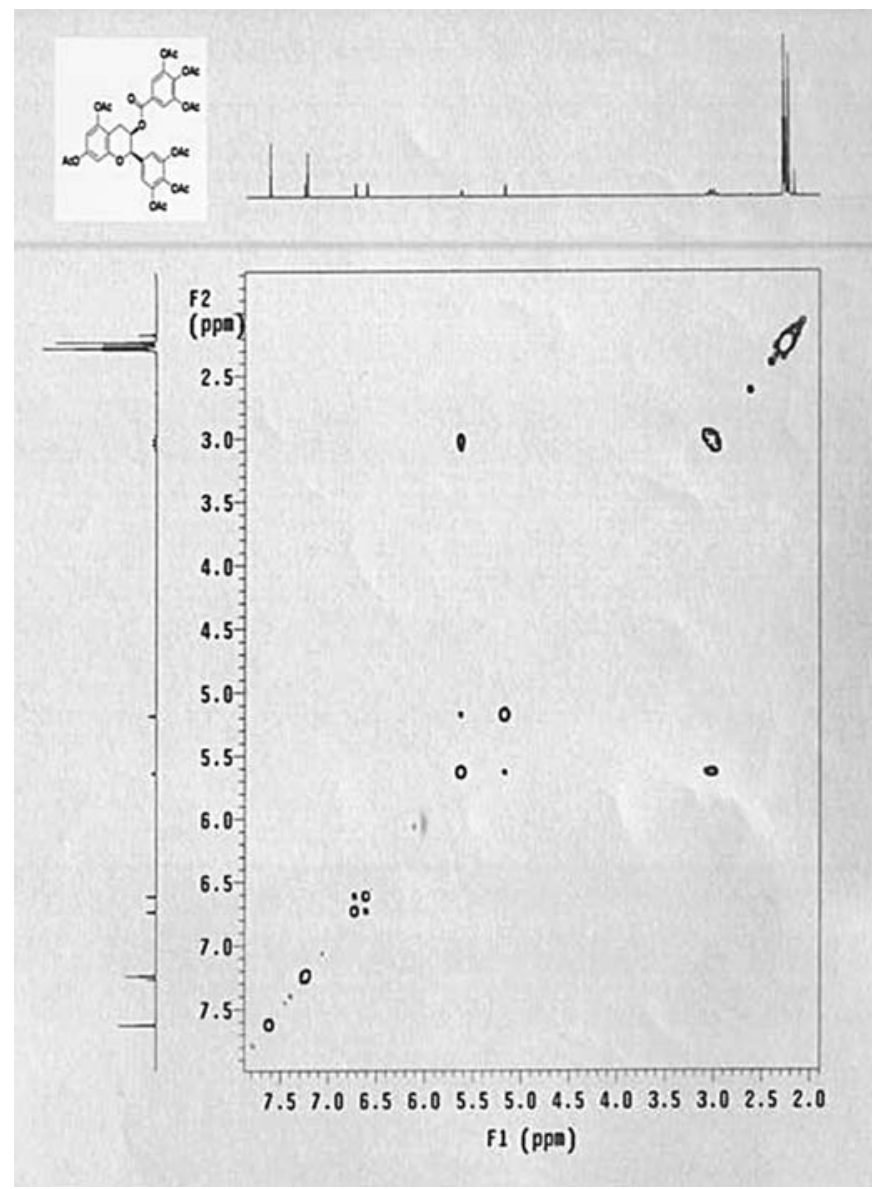

Figure 4. COSY experiment to confirm the presence of pyran ring protons of catechin. For details see Results and discussion.

inhibitory concentration of sodium acetate on MDAMB-231 and SKHep-1 carcinoma cells, we synthesized the octaacetate, in order to compare its activity with its mother compound and sodium acetate. Since esterase hydrolysis of each octaacetate molecular gives out eight equivalent of acetate, it requires $50 \mu \mathrm{M}$ of (-) ECGC for direct comparison while using $400 \mu \mathrm{M}$ of octaacetate as our control. Owing to the lack of spectroscopic information of the octaacetate from existing literature, we performed NMR, MS and 2D COSY experiments to further confirm its structure.

Once we confirmed the successful synthesis of the octaacetate, we performed experiments aimed to investigate whether the presence of acetate at $400 \mu \mathrm{M}$ would have any profound effects together with (-)-EGCG at $50 \mu \mathrm{M}$ when compared with (-)-EGCG octaacetate. As shown in Fig. 6, even though the sum of decrease in terms of intracellular ATP content was not as low as using (-)-EGCG octaacetate ester alone at $50 \mu \mathrm{M}$, the presence of acetate at $400 \mu \mathrm{M}$ leads to a further additional growth inhibitory effect when co-incubated with (-)-EGCG at $50 \mu \mathrm{M}$. These effects were reproducibly observed from both the human cancer cell lines tested.

Entry of protonated acetate would cause acidification and activation of $\mathrm{Na}^{+} / \mathrm{H}^{+}$exchange. Once inside mitochondria, acetate could exhibit their feedback inhibition on citric acid cycle affecting ATP synthesis. This effect is dominant when
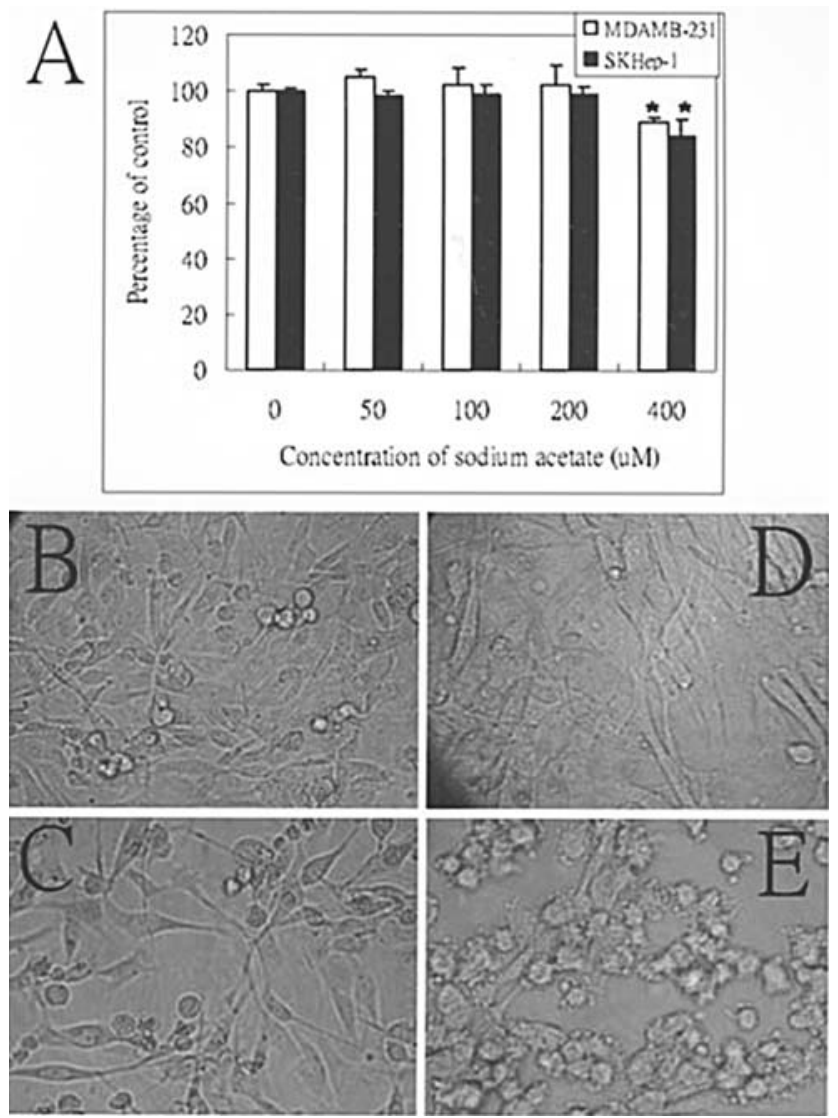

Figure 5. (A) Inhibitory effect of sodium acetate on the growth of MDAMB231 and SKHep-1 human carcinoma cells after $48 \mathrm{~h}$ of incubation as measured by ATP content. Each reading was subtracted by the mean of blanks without cell and sodium acetate but only culture medium and reaction buffer for ATP documentation. Each experiment was performed in triplicate and three independent experiments were done where similar results obtained. Results are shown as one of the representative of the three independent experiments $\left({ }^{*} \mathrm{p}<0.05\right.$ when compared with untreated control). Morphological investigation of (C) MDAMB-231 breast cancer cells and (E) SKHep-1 hepatoma cells after treatment with $400 \mu \mathrm{M}$ of sodium acetate for $48 \mathrm{~h}$ when compared with untreated control (B) MDAMB-231 and (D) SKHep-1 cells.

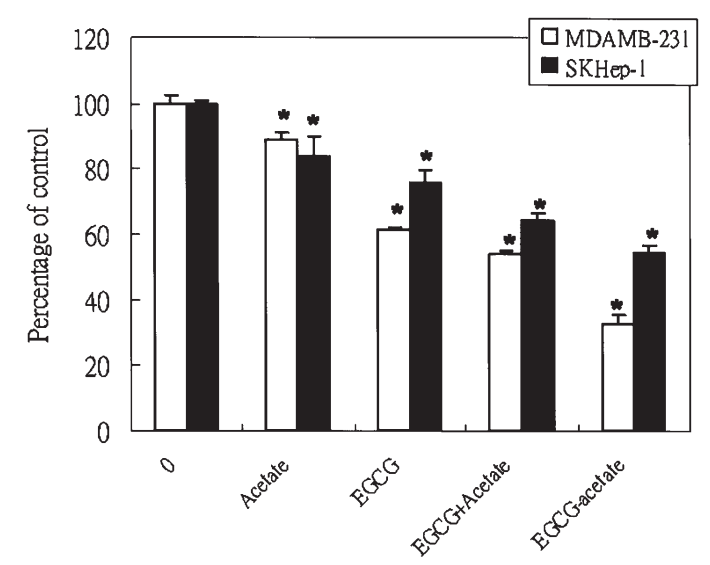

Figure 6. Inhibitory effect of sodium acetate (400 $\mu \mathrm{M}),(-)$-EGCG $(50 \mu \mathrm{M})$, acetate $(400 \mu \mathrm{M})$ plus (-)-EGCG $(50 \mu \mathrm{M})$ or (-)-EGCG octaacetate ester alone $(50 \mu \mathrm{M})$ on the growth of MDAMB-231 and SKHep-1 human carcinoma cells after $48 \mathrm{~h}$ of incubation as measured by ATP content. Each reading was subtracted by the mean of blanks without cell and sodium acetate but only culture medium and reaction buffer for ATP documentation. Each experiment was performed in triplicate and three independent experiments were done and similar results were obtained. Results are shown as one representative of the three independent experiments $\left({ }^{*} \mathrm{p}<0.05\right.$ when compared with untreated control). 
the loading concentration of acetate is greater than $400 \mu \mathrm{M}$. The (-)-EGCG octaacetate ester has a higher cellular permeability when compared with (-)-EGCG. Intracellular esterase can rapidly hydrolyse the (-)-EGCG octaacetate in order to release (-)-EGCG. Therefore, more (-)-EGCG is available with the cell level to exert its biological action even when both (-)-EGCG and (-)-EGCG octaacetate are loaded at the same concentration of $50 \mu \mathrm{M}$. The situation is far more significant and clear as the plasma clearance of (-)-ECGC is very short indeed. This may partly explain why the summated inhibitory effect of acetate at $400 \mu \mathrm{M}$ together with (-)-EGCG at $50 \mu \mathrm{M}$ was lower than that of (-)-EGCG octaacetate ester at $50 \mu \mathrm{M}$. Nevertheless, the release of acetate and/or protonated acetate by intracellular esterase could be part of the explanation to elucidate the improved in vitro cytotoxicity of the (-)-EGCG octaacetate ester on MDAMB-231 and SKHep-1 carcinoma cells.

Recently, we have demonstrated the paradoxical proliferative effect of iron (II) sulphate on human carcinoma cells when documented by the [3-(4,5-dimethylthiazol-2-yl)5-(3-carboxy methoxyphenyl)-2-(4-sulfophenyl)-2Htetrazolium] (MTS) assay colourimetric assay (9). Our results here raise another consideration on novel drug synthesis when using multi-acetates as conjugates to produce ester prodrug because of the inhibitory activity of acetate. We believe that the cytotoxicity of acetate as a side product should be taken into account when designing ester conjugated prodrug and the degree of acetate cytotoxicity would vary with different in vitro conditions. Collectively, it seems that basic fundamental biochemistry and chemistry knowledge is an essential and necessary criterion for those who are working in field of medicinal chemistry.

\section{Acknowledgements}

We acknowledge the support by the internal research grants offered by the Hong Kong Polytechnic University to Dr K.P. Ho (Grant no. PA3F and 879D) and Dr C.H. Chui (Grant no. BB8Q). Professor R. Gambari is sponsored by AIRC (Italian Association for Cancer Research).

\section{References}

1. Mathur S, Picard F, Dossou U, Barassin C, Seidel SB, Kang MJ and Hartmann RW: Evaluation of cell permeation of a potent 5alpha-reductase inhibitor using MALDI-TOF MS. J Enzyme Inhib Med Chem 19: 425-429, 2004.

2. He X, Sugawara M, Takekuma Y and Miyazaki K: Absorption of ester prodrugs in Caco-2 and rat intestine models. Antimicrob Agents Chemother 48: 2604-2609, 2004.

3. Randle PJ, Ewngland PJ and Denton RM: Control of the tricarboxylate cyclie and its interactions with glycolysis during acetate utilization in rat heart. Biochem J 117: 677-695, 1970 .

4. Bristow J, Bier DM and Lange LG: Regulation of adult and fetal myocardial phosphofructokinase. Relief of cooperativity and competition between fructose 2,6-bisphosphate, ATP, and citrate. J Biol Chem 262: 2172-2175, 1987.

5. Kok SHL, Chui CH, Lam WS, Chen J, Lau FY, Wong RSM, Cheng GYM, Lai PBS, Leung TWT, Tang JCO and Chan ASC: Synthesis and structure evaluation of a novel cantharimidie and its cytotoxicity on hepatoma cell line. Bioorg Med Chem Lett 17: 1155-1159, 2007.

6. Kok SHL, Gambari R, Chui CH, Yuen MCW, Lin E, Wong RSM, Lau FY, Cheng GYM, Lam WS, Chan SH, Lam KH, Cheng CH, Lai PBS, Yu MWY, Cheung F, Tang JCO and Chan ASC: Synthesis and anti-cancer activity of benzothiazole containing phthalimide on human carcinoma cell lines. Bioorg Med Chem 16: 3626-3631, 2008

7. Kok SHL, Chui CH, Lam WS, Chen J, Tang JCO, Lau FY, Cheng GYM, Wong RSM and Chan ASC: Induction of apoptosis on carcinoma cells by two synthetic cantharidin analogues. Int J Mol Med 17: 151-157, 2006.

8. Kok SHL, Chui CH, Lam WS, Chen J, Lau FY, Wong RSM, Cheng GYM, Tang WK, Teo ITN, Cheung F, Cheng CH, Chan ASC and Tang JCO: Apoptogenic activity of a synthetic cantharimide in leukaemia: implication on its structural activity relationship. Int J Mol Med 18: 1217-1221, 2006.

9. Kok SHL, Gambari R, Chui CH, Lau FY, Cheng GYM, Lai PBS, Lam WS, Chan ASC, Cheng CH, Teo ITN, Yu MWY, Tang JCO, Cheung F and Wong RSM: Paradoxical proliferative potential of iron (II) sulphate on cancer cells when documented by the 3(4,5-dimethylthiazol-2-yl)-5-(3-carboxymethoxyphenyl)-2-(4sulfophenyl)-2H-tetrazolium (MTS) assay. Int J Mol Med 19: 971-975, 2007. 